\title{
Parosmia agradable a materia fecal propia posterior a la infección por SARS-CoV-2
}

José Halabe-Cherem*, Jorge C. Salado-Burbano y Haiko Nellen-Hummel

Departamento de Medicina Interna, The American British Cowdray Medical Center, Ciudad de México, México

\section{Resumen}

La enfermedad por coronavirus 2019 (COVID-19) ha tenido un impacto mundial trascendente por los millones de muertes que ha causado secundarias a insuficiencia respiratoria. Sin embargo, la enfermedad también se ha asociado a una amplia gama de manifestaciones en otros sistemas. Entre ellas, la presencia de anosmia, la cual ocurre en hasta mitad de los pacientes, se ha vuelto un nuevo dato de alarma para sospechar la infección. Aunque hasta el $90 \%$ de los pacientes afectados presentarán mejoría de sus alteraciones olfatorias dentro del mes posterior a su cuadro, la variedad y gravedad de alteraciones olfatorias claramente no pueden resumirse en la dicotomía de tener o no anosmia. Las parosmias son un tipo de alteración olfatoria caracterizadas por percepciones alteradas de los olores, las cuales pueden reflejar tanto daño a algún nivel del tracto olfatorio, así como la posibilidad de reversibilidad de dicho daño. En el presente manuscrito se describen las posibles alteraciones olfatorias asociadas a COVID-19, su fisiopatología, y potencial significancia clínica.

PALABRAS CLAVE: COVID-19. Trastornos olfatorios. Parosmia. Materia fecal.

\section{Pleasant parosmia with regard to own stool after SARS-CoV-2 infection}

\begin{abstract}
Coronavirus disease 2019 (COVID-19) has had a significant global impact due to the millions of deaths it has caused secondary to respiratory failure. However, the disease has also been associated with a wide array of manifestations in other organ systems. Among them, the presence of anosmia, which occurs in up to half the patients, has become a new sign of alarm to suspect the infection. Although up to $90 \%$ of affected patients will experience an improvement of their olfactory alterations within a month after the infection, the variety and severity of olfactory disturbances clearly cannot be summarized by the dichotomy of having anosmia or not. Parosmias are a type of olfactory dysfunction characterized by altered perception of odors, which can reflect both damage at some level of the olfactory tract, as well as the possibility of reversibility of said damage. The present manuscript describes possible olfactory disturbances associated with COVID-19, their pathophysiology, and potential clinical significance.
\end{abstract}

KEY WORDS: COVID-19. Olfactory disorders. Parosmia. Fecal matter.

Correspondencia:

*José Halabe Cherem

E-mail: jhalabe@ hotmail.com

0016-3813/@ 2021 Academia Nacional de Medicina de México, A.C. Publicado por Permanyer. Este es un artículo open access bajo la licencia CC BY-NC-ND (http://creativecommons.org/licenses/by-nc-nd/4.0/).
Fecha de recepción: 29-09-2021

Fecha de aceptación: 07-10-2021

ste es un artículo open access bajo la licencia
Mex. 2021;157:657-659

Disponible en PubMed 
Más de un año ha transcurrido desde que se reportaron los primeros casos de la enfermedad por coronavirus 2019 (COVID-19) en Wuhan, China, en diciembre del 2019. Desde entonces una pandemia ha sobrepasado al mundo, afectado a billones de personas, y causando la muerte de millones. Aunque el alto impacto de la enfermedad se ha atribuido principalmente a sus manifestaciones pulmonares, se ha vuelto evidente que la COVID-19 es una enfermedad potencialmente multisistémica, capaz de causar trastornos musculoesqueléticos, pulmonares, cardiovasculares, gastrointestinales, renales, neurológicos, cutáneos, endocrinos, hematológicos e inmunitarios ${ }^{1}$.

Aproximadamente uno de cada dos pacientes con COVID-19 presentarán anosmia. Consecuentemente, una pérdida o cambio nuevo del sentido del olfato se ha vuelto un síntoma altamente sugestivo de la infección ${ }^{2}$, causando el que los pacientes se realicen pruebas diagnósticas y se aíslen de los demás. Hasta el $90 \%$ de los pacientes experimentarán una recuperación significativa del sentido del olfato dentro de las cuatro semanas posteriores a su infección.

El patógeno responsable de la COVID-19, el coronavirus 2 del síndrome respiratorio agudo grave (SARS-CoV-2), utiliza proteínas spike presentes en su superficie para acoplarse al receptor de la enzima convertidora de angiotensina 2 (ACE2). Dicho receptor se expresa en varios tejidos corporales, incluyendo los bulbos olfatorios, epitelio de la vía aérea, parénquima pulmonar, endotelio vascular, riñón, intestino delgado y sistema nervioso central (SNC) ${ }^{3}$.

Dentro del SNC, el receptor de ACE2 se expresa en neuronas, astrocitos y oligodendrocitos; y se concentra en la sustancia negra, ventrículos, giro temporal medio y corteza cingulada posterior. Hay varios mecanismos plausibles por los cuales el virus puede lograr la neuroinvasión, incluyendo la entrada por el nervio olfatorio, transferencia sináptica a lo largo de neuronas infectadas, migración leucocitaria a través de la barrera hematoencefálica e infección del endotelio vascular ${ }^{3}$.

Aunque los síntomas olfatorios asociados con COVID-19 comúnmente han sido descritos como una pérdida súbita del olfato o gusto, existen una amplia gama de manifestaciones de disfunción quimiosensitiva. Estos incluyen al olfato ortonasal o retronasal alterado, gusto alterado, parosmia, parageusia y fantosmia. Además de los distintos tipos de alteraciones, también existen distintos niveles de gravedad, como la hiposmia, anosmia, hiperosmia, hipogeusia y ageusia $^{4}$.
Aunque la mayoría de los pacientes que presentan disfunción olfatoria asociada a la infección por SARSCoV-2 pueden identificar al síntoma fácilmente, los instrumentos para poder medir dicha afección de manera objetiva (p. ej., herramientas de valoración psicofísicas que valoran por lo menos uno de los siguientes: umbral, discriminación o identificación de olores) a menudo no están disponibles, al igual que los profesionales de la salud capacitados para poder realizar este tipo de pruebas. Adicionalmente, el potencial que tiene el virus para causar insuficiencia respiratoria y la dificultad añadida de tener que trabajar con equipo de protección personal a menudo limitan que tan detallada puede ser la exploración física o historia clínica de estos pacientes, pudiendo afectar que tanta información se recaba con respeto a alteraciones olfatorias ${ }^{4}$.

Tras atender más de tres mil pacientes con COVID19, notamos una manifestación distintiva de la recuperación olfatoria. Más de 20 pacientes acudieron a citas de seguimiento reportando que los últimos olores que recuperaron la capacidad de poder apreciar fueron los de sus propios cuerpos, y en particular, de su materia fecal. Varios de estos pacientes también reportaron que estos olores incluso ya les parecían agradables.

Estos casos de disfunción olfatoria se considerarían parosmias, es decir, la percepción alterada de un olor. Otros términos relacionados que considerar incluyen disosmia/cacosmia (una percepción usualmente desagradable de un olor) y fantosmia (la percepción de un olor no existente). Se cree que las parosmias ocurren debido a disparos efápticos en neuronas desmielinizadas, es decir, cortocircuitos eléctricos no mediados por neurotransmisores. De manera paradójica, la presencia de estos síntomas a menudo sugiere daño a estructuras del tracto olfatorio, al igual que el potencial de estas estructuras para poder sanar. Dicho proceso puede tomar años, pero en algunos casos el daño puede ser irreversible dependiendo de la causa ${ }^{5}$.

Las parosmias agradables se consideran raras y se desconoce si conllevan una significancia distinta a las disosmias (desagradables) más comúnmente descritas. Otro factor interesante que considerar es que los pacientes refieren estas parosmias al oler su propia materia fecal. Más allá de considerarse un material de desperdicio genérico resultante del proceso digestivo, la material fecal tiene el potencial de reflejar varios aspectos de la salud general de un individuo. La genética, dieta, proceso digestivo y microbioma de un 
paciente pueden influir en varios aspectos de la homeostasis, incluyendo su metabolismo, salud del aparato digestivo, efectos neuronales e inflamación ${ }^{6}$. Considerando el interés reciente que se ha tenido por investigar los potenciales usos de los trasplantes de microbiota fecal, cada vez se vuelve más claro que la materia decal no solo es un material de desperdicio, y que de hecho puede tener un rol tanto fisiológico como patológico en la vida de las personas. La razón para la especificidad de los síntomas de nuestros pacientes (p. ej., parosmias que ocurren con el olor de la materia fecal) no es clara, pero podría representar cambios en los elementos previamente mencionados relevantes para la composición fecal. Estas parosmias inusualmente agradables incluso podrían representar la habilidad para detectar dichos cambios.

Las alteraciones en el olfato tienden a volverse más frecuentes conforme las personas envejecen, pero también pueden asociarse a ciertas patologías como traumatismos craneoencefálicos, exposición a ciertos medicamentos o toxinas (incluyendo al consumo crónico de alcohol y tabaquismo), varios trastornos neurodegenerativos (incluyendo la enfermedad de Alzheimer, enfermedad de Parkinson, demencia con cuerpos de Lewy y demencia frontotemporal), esclerosis múltiple, migraña, epilepsia, diabetes mellitus, hipotiroidismo, enfermedad hepática crónica, enfermedad renal crónica y deficiencia de vitamina B12 o folato ${ }^{7}$.

Todavía no se sabe con certeza por qué algunos pacientes desarrollan anosmia durante la infección por SARS-CoV-2 y otros no. Además, no se sabe si el haber presentado este síntoma pudiera asociarse a futuro con alguna de las comorbilidades previamente mencionadas. Las parosmias agradables a olores corporales propios descritas por nuestros pacientes durante su etapa de recuperación olfatoria no parecen haber sido previamente descritas y la significancia de dicho síntoma también continúa siendo un enigma.

Consideramos de interés el reportar este síntoma aparentemente no descrito para documentar su existencia y mantenerlo en mente junto con las otras alteraciones olfatorias conforme se sigue brindando atención y dando seguimiento a los pacientes infectados por SARS-CoV-2. Además, el darle mayor reconocimiento a estas parosmias agradables podría contribuir al estudio y entendimiento de otros trastornos olfatorios.

\section{Financiamiento}

No se contó con ningún financiamiento para la elaboración del manuscrito.

\section{Conflicto de intereses}

Los autores declaran no tener conflicto de intereses.

\section{Responsabilidades éticas}

Protección de personas y animales. Los autores declaran que para esta investigación no se han realizado experimentos en seres humanos ni en animales.

Confidencialidad de los datos. Los autores declaran que han seguido los protocolos de su centro de trabajo sobre la publicación de datos de pacientes.

Derecho a la privacidad y consentimiento informado. Los autores declaran que en este artículo no aparecen datos de pacientes.

\section{Bibliografía}

1. Ramos-Casals M, Brito-Zerón P, Mariette X. Systemic and organ-specific immune-related manifestations of COVID-19. Nat Rev Rheumatol. 2021;17(6):315-32.

2. Walker A, Pottinger G, Scott A, Hopkins C. Anosmia and loss of smell in the era of covid-19. BMJ. 2020;370:m2808.

3. Zubair AS, McAlpine LS, Gardin T, Farhadian S, Kuruvilla DE, Spudich S. Neuropathogenesis and neurologic manifestations of the coronaviruses in the age of coronavirus disease 2019. JAMA Neurol. 2020;77(8):1018-27.

4. Whitcroft KL, Hummel T. Olfactory dysfunction in COVID-19 - Diagnosis and Management. JAMA. 2020;323(24):2512-4.

5. Hawkes C. Parosmia: treatment, mechanism, and types. BMJ. 2020;371:m4739.

6. Fan $Y$, Pedersen $\mathrm{O}$. Gut microbiota in human metabolic health and disease. Nat Rev Microbiol. 2021;19(1):55-71.

7. DeVere R. Disorders of taste and smell. Continuum (Minneap Minn). 2017;23(2):421-26. 